\title{
A coplanar waveguide fed UWB antenna using embedded E-shaped structure with WLAN band-rejection
}

\author{
Han Xu' ${ }^{1}$ Kai-Da Xu' ${ }^{1,2}$, Wei Nie ${ }^{3}$, Yan-Hui Liu ${ }^{1}$ \\ ${ }^{1}$ Department of Electronic Science, Xiamen University, Xiamen 361005, China \\ ${ }^{2}$ Shenzhen Research Institute of Xiamen University, Shenzhen 518057, China \\ 3 School of Communication and Information Engineering, Chongqing University of Posts and Telecommunications, \\ Chongqing \\ *Corresponding author Email: kaidaxu@xmu.edu.cn
}

\begin{abstract}
A compact coplanar waveguide (CPW)-fed ultra-wideband (UWB) monopole antenna using embedded E-shaped structure with wireless local area network (WLAN) band-rejection is presented. The introduction of this E-shaped structure working as the radiator can enhance the impedance bandwidth of the UWB antenna without increasing the overall size. For preventing the interference from WLAN system, a pair of L-shaped stubs are connected to the ground of UWB antenna to create the rejected band. The center frequency of this rejected band is about $5.5 \mathrm{GHz}$ with the rejection range of 5.2 5.8 GHz. Good agreement can be observed between the simulated and measured results.
\end{abstract}

Keywords: band-rejection, monopole antenna, printed antenna, ultra-wideband antenna

\section{Introduction}

Nowadays, the ultra-wideband (UWB) techniques with low spectral power density and high data rates have drawn great attention, which operate at the frequency range from 3.1 to $10.6 \mathrm{GHz}$ released by the Federal Communication Commission (FCC) [1]. However, some wireless communication systems, such as the wireless local area network (WLAN) covering from 5.15 to $5.825 \mathrm{GHz}$ will cause electromagnetic interference to the UWB applications. In order to solve this problem, several methods have been proposed to create the notches within UWB frequency range [2-10]. One of these approaches is introducing some resonators be- side feedline [2] or on the back of substrate [3, 4], which will increase the complication of the structure. Some strips with different shapes (e.g., rectangular shape [5]) are also added to the radiator of UWB antennas to prevent interferential frequency. In [6], two pairs of stubs are added to the radiator for the rejected bands generation. Another widely used band-notched generation technique is etching slots on the radiators [7-10], such as pi-slot [7], U-slot [8] and so on. In [9], two slots are directly added to the antenna radiator so that two corresponding notch bands can be introduced. Additionally, the MEMS technology is employed in the UWB antenna to control the rejected band, but it makes the antenna structure more complex and the cost is relatively high [11]. In [12], a pair of compact in-band full-duplex relay antennas with wavetraps for isolation improvement are introduced. Several short-circuited quarter-wavelength patches are employed as wavetraps to suppress the mutual coupling between the antennas.

In this paper, a novel compact coplanar waveguide (CPW)-fed E-shaped UWB monopole antenna with WLAN band-rejection is presented. The embedded E-shaped structure performing as the radiator is designed to improve the impedance bandwidth of the UWB antenna without increasing the overall size. Then, a pair of L-shaped parasitic stubs is connected to the ground in order to realize WLAN band-rejection. Finally, a sample of this proposed antenna is fabricated and measured to validate the design concept. 


\section{Antenna design}

The evolution of the proposed CPW-fed UWB antenna with band-rejection is shown in Figure 1, where the four antennas are all designed on a FR4 substrate with a thickness of $0.8 \mathrm{~mm}$ and a dielectric constant of 4.4. As shown in Figure 1(a), it is a traditional rectangular monopole antenna named Antenna_1 whose bandwidth is from 3.8 to $12 \mathrm{GHz}$ with $\left|\mathrm{S}_{11}\right|<-10 \mathrm{~dB}$, as shown in Figure 2. The bandwidth of Antenna_1 cannot satisfy the requirement of UWB application. In order to improve the antenna bandwidth, an E-shaped structure is applied to the monopole, i.e., Antenna_2, as presented in Figure 1(b). The bandwidth of Antenna_2 is from 3.5 to $12 \mathrm{GHz}$ with $\left|\mathrm{S}_{11}\right|<-10 \mathrm{~dB}$ as shown in Figure 2, which is wider than that of Antenna_1. However, the bandwidth still does not meet the UWB frequency range of $3.1 \sim 10.6 \mathrm{GHz}$. Thus, to further increase the bandwidth, three stubs of Antenna_2 can be modified to smaller E-shaped ones as illustrated in Figure 1(c) so that the bandwidth can be expanded once again. It can be seen from Figure 2 that owing to the embedded E-shaped structures, the bandwidth has been enhanced obviously, which is from 2.8 to $12 \mathrm{GHz}$ with $\left|\mathrm{S}_{11}\right|<-10$ $\mathrm{dB}$.

The introduction of E-shaped stubs does not generate additional resonant modes, but it can decrease the operating frequency of the fundamental resonant mode, resulting in the bandwidth enhancement of the antenna. As shown in Figure 2, the resonant modes of Antenna_2 are moved toward the lower frequency due to the E-shaped structure compared with those of Antenna_1. For the Antenna_3, the fundamental resonant mode is changed downward from 4.94 to $3.90 \mathrm{GHz}$, while the second resonance is also moved toward the lower frequency. Moreover, the third resonant mode shifts from the frequency point larger than $12 \mathrm{GHz}$ down to about $11 \mathrm{GHz}$ with the help of three smaller embedded E-shaped structures. Therefore, the bandwidth of the antenna can be enhanced using embedded E-shaped structure due to the movement of resonant modes, but without the increase of the antenna size.

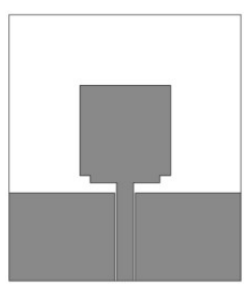

(a)

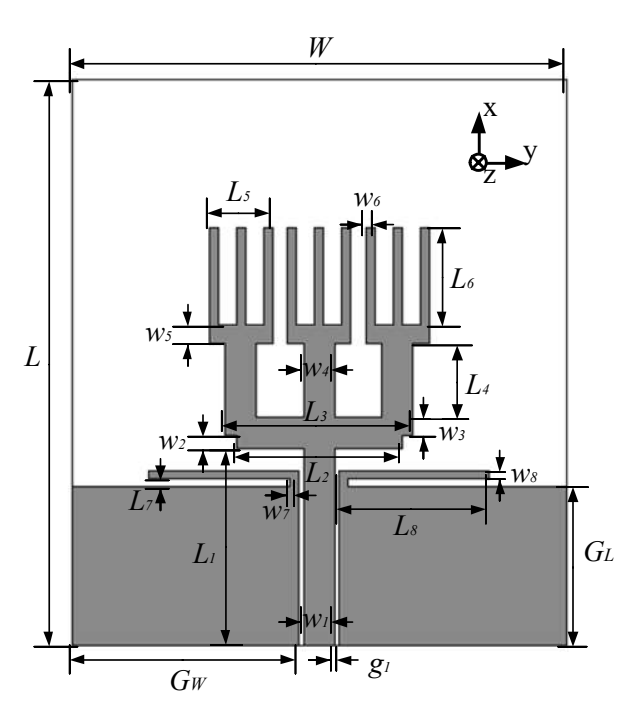

(d)

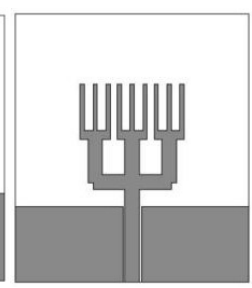

(c)
Figure 1 Revolution of the proposed antenna, (a) Antenna_1, (b) Antenna_2, (c) Antenna_3, and (d) Antenna_4, i.e., the proposed antenna.

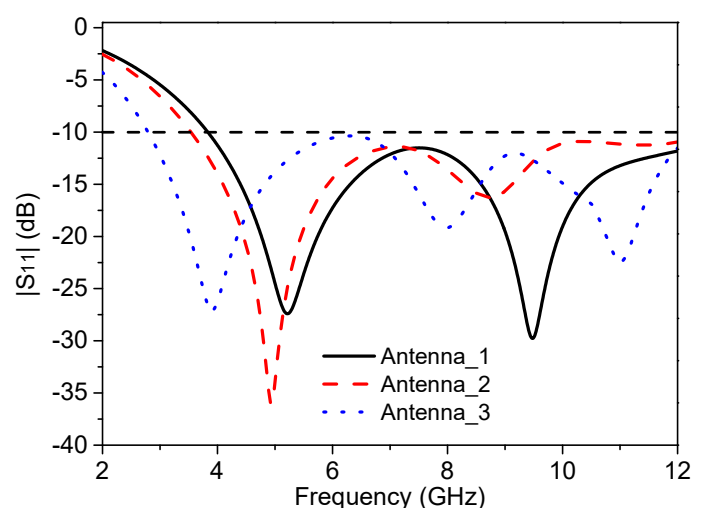

Figure 2 Simulated reflection coefficients of the Antenna_1, Antenna_2 and Antenna_3.

Although the stubs will not introduce resonant modes, they change the position of existed resonant modes. Figure 3 shows the simulation of Antenna_3 with different parameters. In Figure 3(a), the three resonant modes move to the lower frequency with the in- 
crease of $L_{6}$ from $8 \mathrm{~mm}$ to $10 \mathrm{~mm}$, causing the enhancement of bandwidth. However, when the $L_{6}$ is more than $9.5 \mathrm{~mm}$, the $\left|\mathrm{S}_{11}\right|$ in operation band will over the $-10 \mathrm{~dB}$. In Figure 3(b), it can be found that the change of $w_{6}$ can improve the reflection coefficient of the antenna. Therefore, these two parameters can be adjusted to achieve better bandwidth and performance.

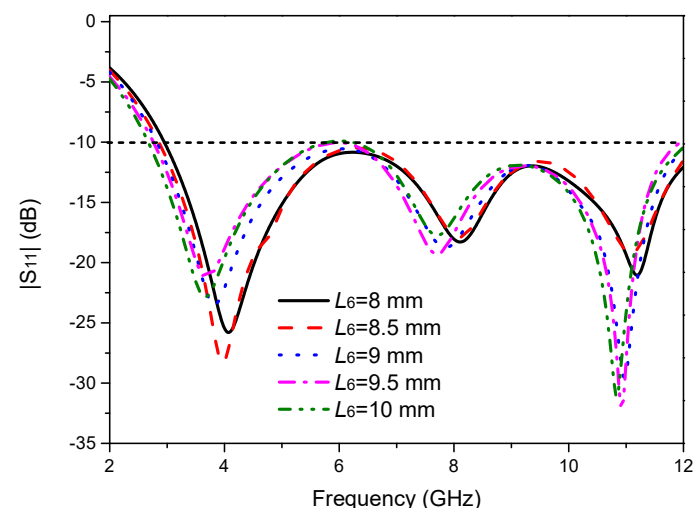

(a)

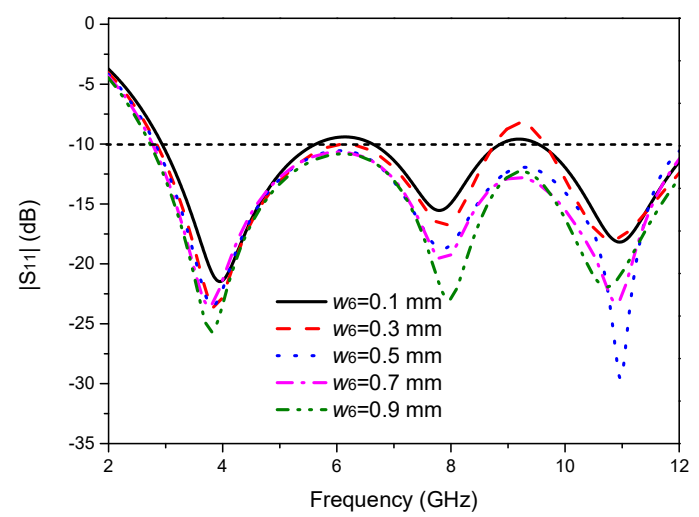

(b)

Figure 3 Simulated $\left|\mathrm{S}_{11}\right|$ of Antenna_3 with different (a) $L_{6}$ and (b) $w_{6}$.

To prevent the interference from WLAN, a pair of L-shaped parasitic stubs is connected to the ground based on Antenna_3, as illustrated in Figure 1(d). Figure 4 illustrates the comparisons of simulated reflection coefficient between Antenna 3 and Antenna 4 (i.e., the proposed UWB antenna with WLAN band-rejection). The L-shaped parasitic stubs act as quarter-wavelength resonators which can change the current distribution on the surface of ground and antenna. As shown in Figure 5 , the current distribution mainly concentrates on the
L-shaped stubs while less current distributes on the radiator of the antenna. As a result, a rejected band at around $5.5 \mathrm{GHz}$ has been created and the antenna cannot transmit electromagnetic wave well at this notched band. To further investigate the effects of these parasitic stubs, some parametric studies have been analyzed as following.

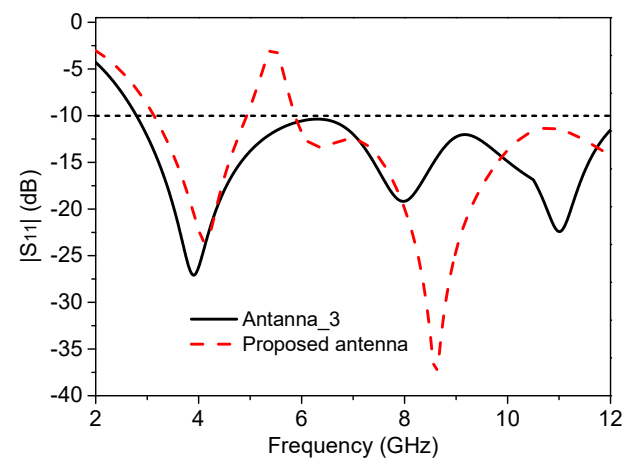

Figure 4 Simulated reflection coefficients of Antenna_3 and the proposed antenna.

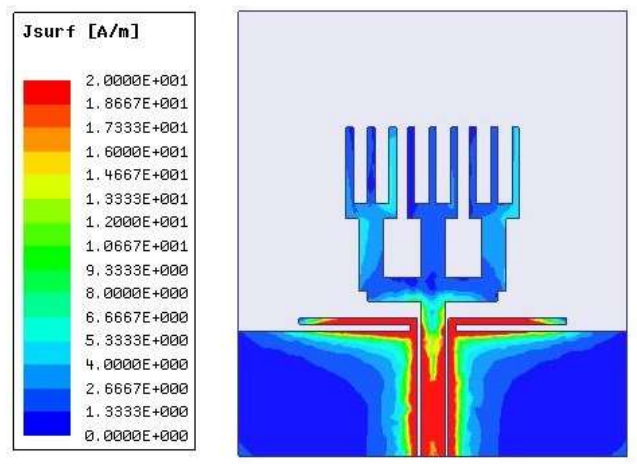

Figure 5 Simulated current distribution of the proposed antenna at $5.5 \mathrm{GHz}$.

The L-shaped stub functions as a quarter-wavelength resonator actually and the rejected resonance frequency can be derived as

$$
f_{\text {reject }}=\frac{c}{4 L_{\text {total }} \sqrt{\varepsilon_{\text {eff }}}}
$$

where $c$ is the speed of light in free space, $\varepsilon_{\text {eff }}$ denotes the effective dielectric constant of the substrate, and $L_{\text {total }}$ is the total length of stub, i.e., $L_{\text {total }}=L_{7}+L_{8}$, as seen in Figure 1(d). It obviously that when the length of stubs increases, the center frequency of the rejected 
band will decrease. Therefore, using Equation (1), the center frequency of the rejected band can be calculated at the beginning of antenna design and then be confirmed by adjusting the stub parameters to meet the design requirements.

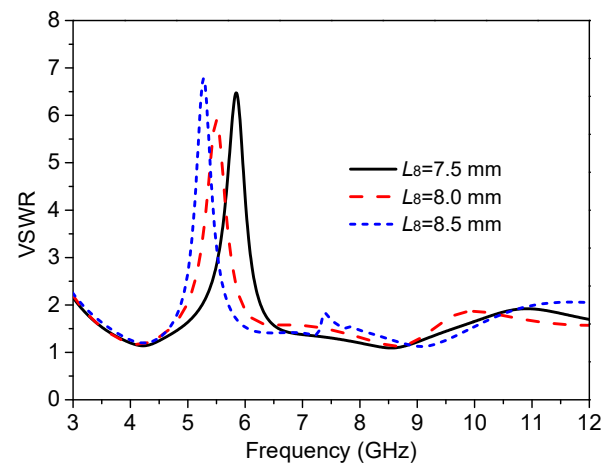

(a)

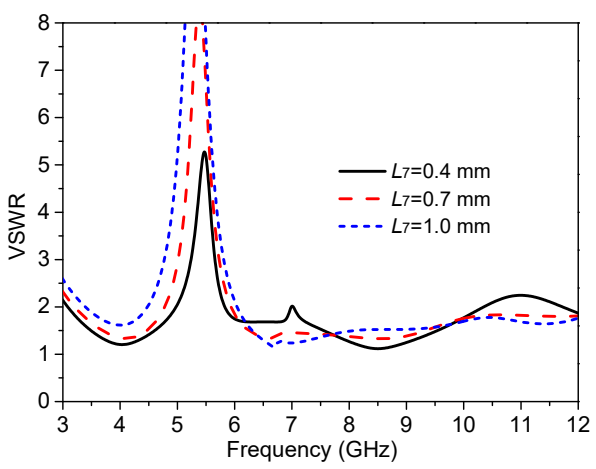

(b)

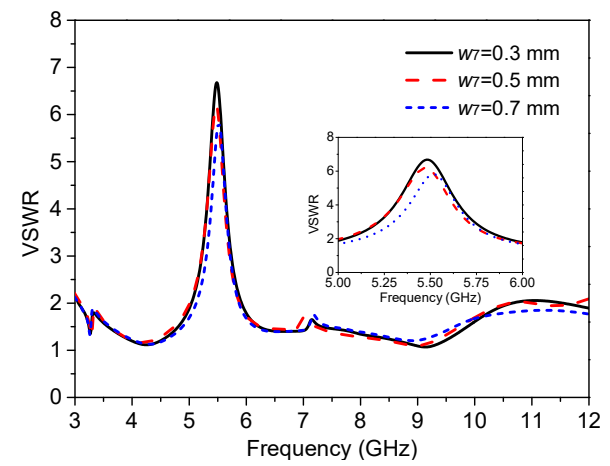

(c)

Figure 6 Simulated VSWR of the proposed antenna with different (a) $L_{8}$, (b) $L_{7}$ and (c) $w_{7}$.

Figure 6 exhibits the effect of L-shaped parasitic stubs on Voltage Standing Wave Ratio (VSWR) of the proposed antenna versus frequency. The center frequency of rejected band will shift from 5.84 to 5.27
$\mathrm{GHz}$ when $L_{8}$ increases from 7.5 to $8.5 \mathrm{~mm}$ with $w_{7}=$ $0.4 \mathrm{~mm}$ and $L_{7}=0.5 \mathrm{~mm}$, as shown in Figure 6(a). The increase of $L_{8}$ will lead to the decrease of rejected resonance frequency, which can also be obtained from Equation (1). When $L_{7}$ increases from 0.4 to $1 \mathrm{~mm}$, the rejection characteristics of the notched band will be better and the bandwidth will be also broadened as seen in Figure 6(b). Figure 6(c) illustrates the frequency responses of the VSWR with different stub widths $\mathrm{w}_{7}$, where a slight effect on the rejected band occurs with varied $w_{7}$. Accordingly, at the design of an UWB antenna with a WLAN rejected band, Equation (1) can be used to calculate the analytical solution of the stub length firstly to make the center frequency of the rejected band located at WLAN system. Then, several simulations should be done to explore and attain the optimum values of $L_{7}, L_{8}$ and $w_{7}$. These three parameters can be utilized to adjust the center frequency and bandwidth of the rejected band.

\section{Experimental results and discussions}

\subsection{Experimental results}

According to the above-mentioned analysis, a printed UWB with rejected band, whose structure has been illustrated in Figure 1(d), is designed and fabricated. The proposed antenna is constructed on an FR4 substrate with a thickness of $0.8 \mathrm{~mm}$ and relative dielectric constant of 4.4. The dimensions of the antenna are optimized and finally chosen as tabulated in Table 1 (unit: $\mathrm{mm})$. Figure 7 shows the photograph of the fabricated antenna.

Table 1 Dimensions of the proposed antenna (unit: $\mathrm{mm}$ )

\begin{tabular}{|c|c|c|c|c|}
\hline$L$ & $W$ & $G_{\mathrm{L}}$ & $G_{\mathrm{w}}$ & $L_{1}$ \\
\hline 30.72 & 26.85 & 8.64 & 12.34 & 10.66 \\
\hline \hline$L_{2}$ & $L_{3}$ & $L_{4}$ & $L_{5}$ & $L_{6}$ \\
\hline 8.98 & 10.18 & 4.04 & 3.45 & 5.32 \\
\hline \hline$L_{7}$ & $L_{8}$ & $w_{1}$ & $w_{2}$ & $w_{3}$ \\
\hline 0.45 & 8.16 & 1.69 & 0.7 & 1 \\
\hline \hline$w_{4}$ & $w_{5}$ & $w_{6}$ & $w_{7}$ & $g_{1}$ \\
\hline 1.68 & 1 & 0.49 & 0.42 & 0.24 \\
\hline
\end{tabular}




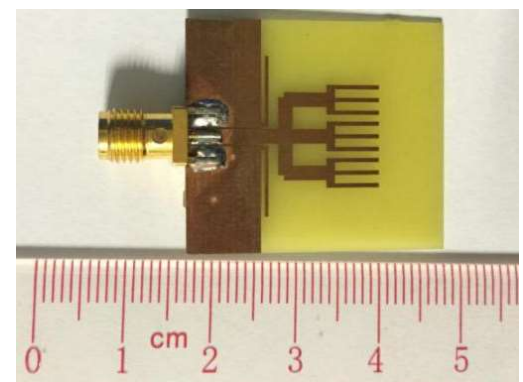

Figure 7 Photograph of the fabricated antenna.

Figure 8 demonstrates simulated and measured reflection coefficients and peak gains of the proposed band-rejected UWB antenna. It can be seen that the designed antenna achieves super wideband performance from 3.1 to $12 \mathrm{GHz}$ with $\left|\mathrm{S}_{11}\right|<-10 \mathrm{~dB}$ which satisfies the requirements of UWB antennas, regardless of a rejected band from $5.2 \mathrm{GHz}$ to $5.8 \mathrm{GHz}$. The center frequency of the rejected band is at around $5.5 \mathrm{GHz}$. A stable gain with slight increase can be observed at the UWB operating frequencies, except for a drastic decrease at the rejected band of around $5.5 \mathrm{GHz}$. Good agreement between the simulated and measured results can be observed, whereas small disagreement still exists which may be attributed to the SMA connector soldering and measurement error. Figure 9 plots the simulated and measured far-field radiation patterns of the proposed antenna in the E-plane (xoy-plane) and H-plane (yoz-plane) at $4 \mathrm{GHz}, 6 \mathrm{GHz}$ and $9 \mathrm{GHz}$. It can be observed that the antenna has good dipole-like radiation patterns in E-plane and omnidirectional patterns in H-plane.

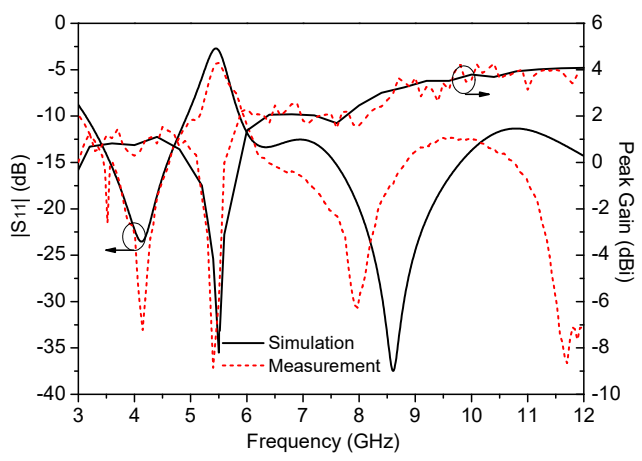

Figure 8 Simulated and measured $S_{11}$ and peak gains of the proposed antenna.

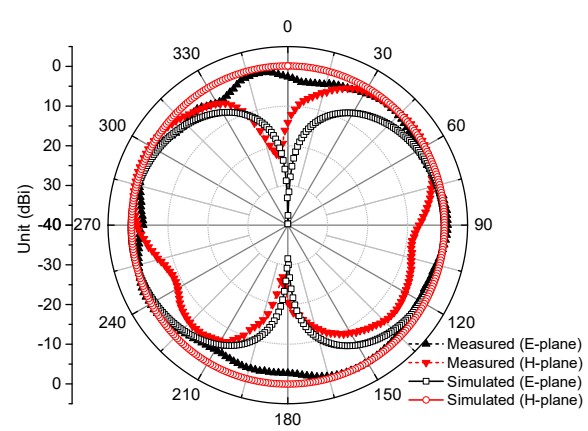

(a)

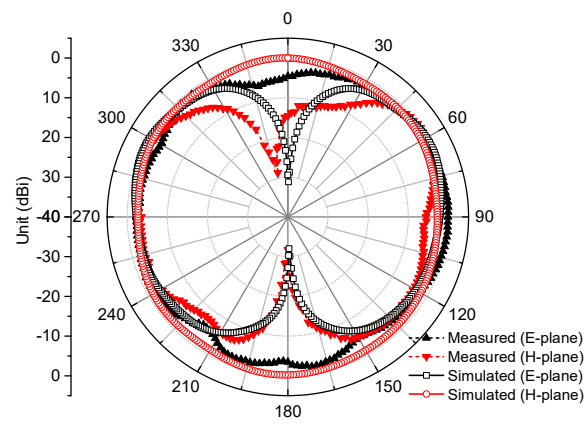

(b)

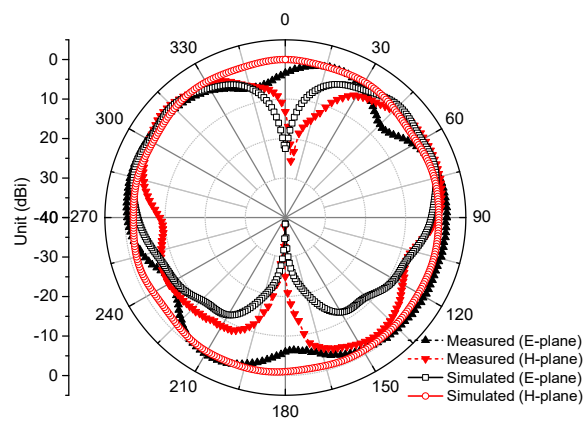

(c)

Figure 9 Measured and simulated radiation patterns of the proposed antenna in E- and H-plane at (a) $4 \mathrm{GHz}$, (b) $6 \mathrm{GHz}$ and (c) $9 \mathrm{GHz}$.

\subsection{Discussions}

The simulated cross-polarizations of the Antenna_1, Antenna_2, Antenna_3 and Antenna_4 in E-plane and $\mathrm{H}$-plane at different frequencies are illustrated in Figure 10. The cross-polarization levels in E-plane are below $-32 \mathrm{~dB},-25 \mathrm{~dB}$ and $-23 \mathrm{~dB}$ at 4,6 , and $9 \mathrm{GHz}$, respectively. At the higher frequency point, the cross-polarization level is relatively high, especially in H-plane. However, with the evolution of antennas, the cross-polarization levels of these four antennas at the 
same frequency in E-plane or H-plane almost keep unchanged, which indicates that the embedded E-shaped structures and the L-shaped stubs have little effect on the cross-polarizations of the antennas. (a)

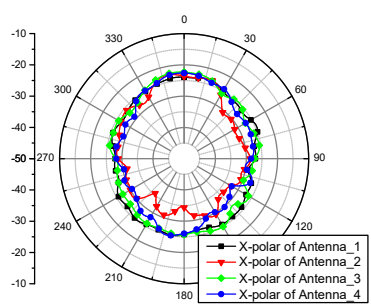

(c)

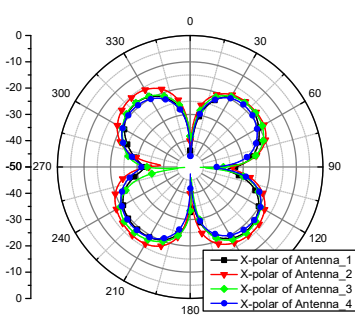

(e)

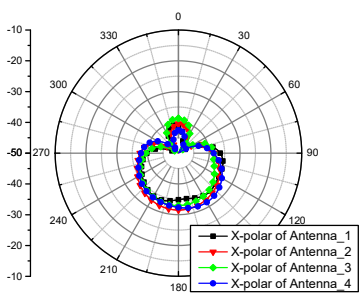

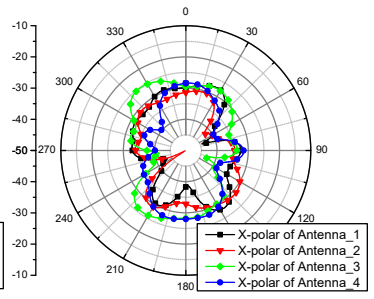

(b)

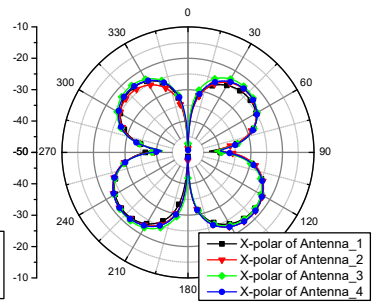

(d)

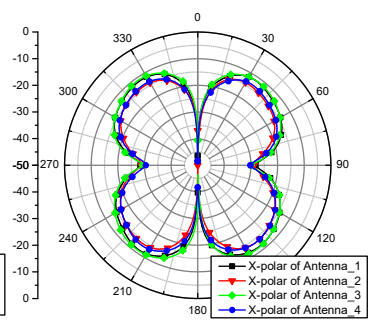

(f)
Figure 10 Simulated cross-polarizations of the Antenna 1, Antenna 2, Antenna 3 and Antenna 4 in E-plane at (a) $4 \mathrm{GHz}$, (b) $6 \mathrm{GHz}$, and (c) $9 \mathrm{GHz}$, and in H-plane at (d) $4 \mathrm{GHz}$, (e) $6 \mathrm{GHz}$ and (f) $9 \mathrm{GHz}$.

As above analyzed in Section 2, one rejected band is introduced because of the application of a pair of L-shaped stubs, while multiband rejection can also be obtained when several stubs are used. For instance, using two pairs of L-shaped parasitic stubs, Figure 11 shows a dual band-notched UWB antenna, i.e., Antenna_5, whose simulated VSWR and that of Antenna_4 are compared in Figure 12. The Antenna_5 is designed based on Antenna_4 and all parameters of these two antennas are the same except the added pair of L-shaped stubs. As shown in Figure 12, it can be found that the Antenna_5 has one more rejected band than that of its counterpart Antenna_4. When the extra pair of stubs are added to the Antenna_4, a new rejected band can be generated, while the VSWR at other frequencies is almost unchanged. Therefore, the technique reported in our work that using stub pairs is suitable for the rejection of multiple bands.

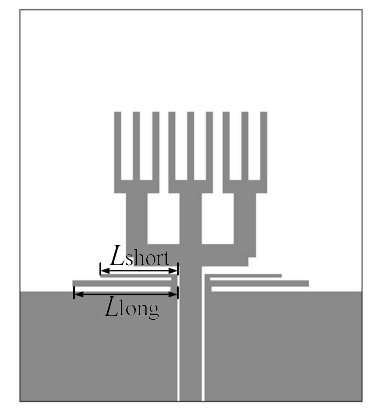

Figure 11 Sketch of the Antenna_5.

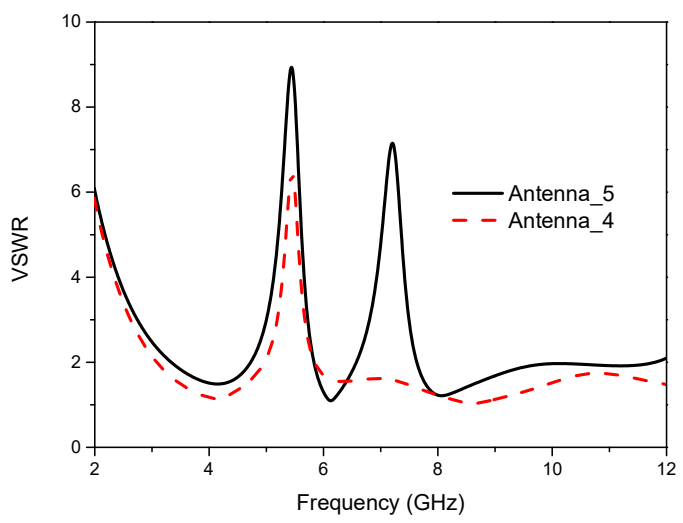

Figure 12 Simulated VSWR of antennas with one and two pairs of stubs.

The simulated VSWRs of Antenna_5 against different parameters are shown in Figure 13. The center frequencies of these two rejected bands are independent each other, which can be controlled by the lengths of their corresponding stub pairs. As shown in Figure 13(a), when the length of the long stub pairs $L_{\text {long }}$ increases from 7 to $8 \mathrm{~mm}$ under the condition of other fixed parameters, the center frequency of the first rejected band is moved toward the lower frequency, while that of the second rejected band almost keeps unchanged. Similarly, as shown in Figure 13(b), when the length of the short stub pairs $L_{\text {short }}$ increases from 6 to $6.8 \mathrm{~mm}$, the center frequency of the second rejected band shifts toward the lower frequency as well, while 
that of the first rejected band remains fixed. Therefore, these two rejected bands can be independently controlled by the lengths of long and short stubs, respectively.

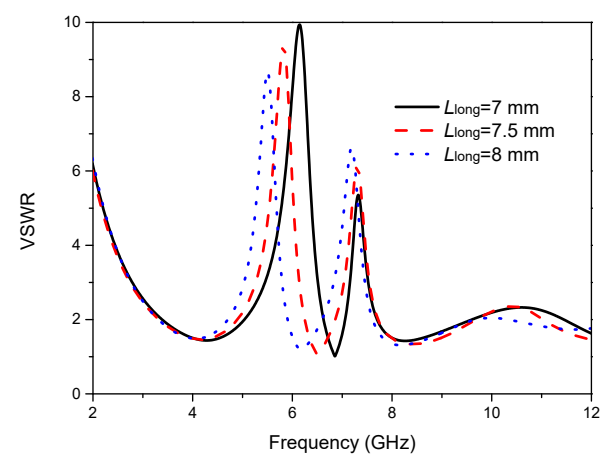

(a)

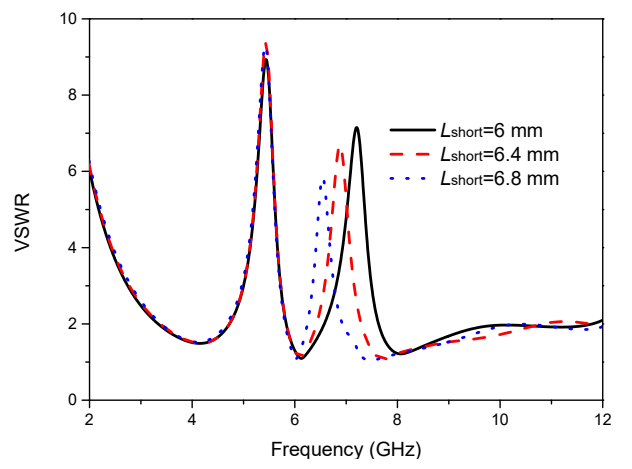

(b)

Figure 13 Simulated VSWRs of the Antenna_5 against different (a) $L_{\text {long }}$ and (b) $L_{\text {short }}$.

The simulated radiation patterns of Antenna_4 and Antenna_5 at $4 \mathrm{GHz}, 6 \mathrm{GHz}$ and $9 \mathrm{GHz}$ are shown in Figure 14. It is obvious that the radiation characteristics of Antenna_4 and Antenna_5 are almost the same in both E-plane and H-plane. This indicates that the added stubs have little effect on the performance of the antenna.

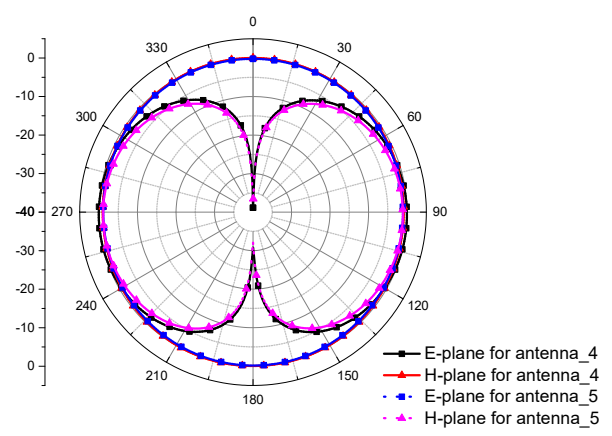

(a)

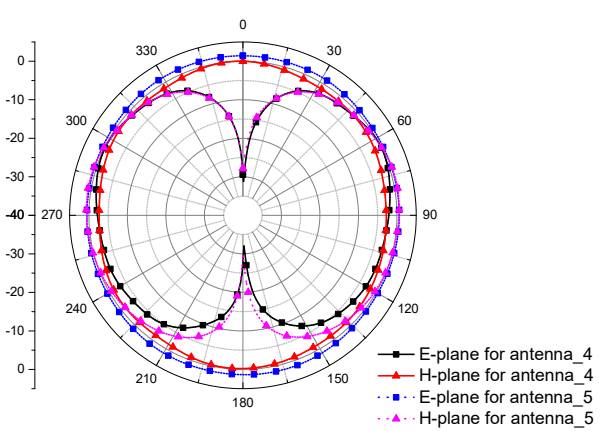

(b)

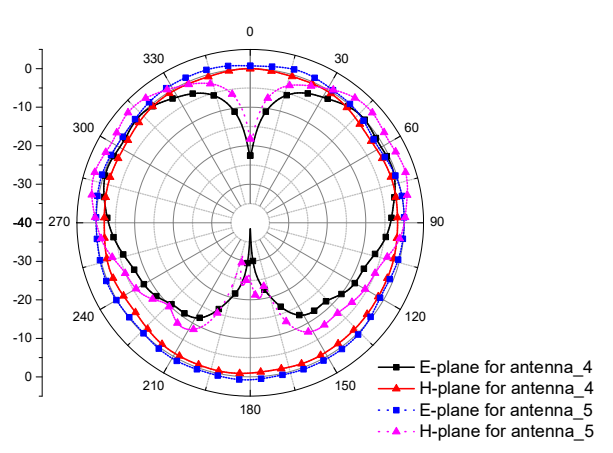

(c)

Figure 14 Simulated radiation patterns of Antenna_4 and Antenna_5 at (a) $4 \mathrm{GHz}$, (b) $6 \mathrm{GHz}$ and (c) $9 \mathrm{GHz}$.

\section{Conclusion}

In this paper, we present a CPW-fed UWB antenna using embedded E-shaped structure to enhance the impedance bandwidth. In order to prevent the interference caused by the WLAN system, a pair of L-shape stubs is connected to the ground of UWB antenna to generate the rejected band. Simulated and measured results including reflection coefficients, peak gains and radiation patterns are in good agreement. Due to its miniaturized size and simple design procedure, the proposed antenna is attractive to apply in UWB wireless systems.

\section{Acknowledgment}

This work was partially supported by the National Natural Science Foundation of China (No. 61601390), and Shenzhen Science and Technology Innovation Project (No. JCYJ20170306141249935).

\section{References}

[1] Fed. Commun. Comm, "First report and order, revi- 
sion of part 15 of the commission's rule regarding ultra wideband transmission systems", FCC 02-48 Apr. 22, 2002 .

[2] J.H. Wang, Y.Z. Yin, and X.L. Liu, "Triple band-notched ultra-wideband antenna using a pair of novel symmetrical resonators", IET Microw. Antennas Propag., vol. 8, no. 14, pp. 1154-1160, 2014.

[3] R. Azim, M.T. Islam, and A.T. Movashsher, "Dual band-notch UWB antenna with single tri-arm resonator", IEEE Antennas Wireless Propag. Lett. vol. 12, no. 1, pp. 670-673, 2014

[4] J.Y. Siddiqui, C. Saha and Y.M.M. Antar, "Compact SRR loaded UWB circular monopole antenna with frequency notch characteristics", IEEE Trans. Antennas Propag., vol. 62, no. 8, pp. 4015-4020, 2014.

[5] K.S. Ryu and A.A. Kishk, "UWB antenna with single or dual band-notches for lower WLAN band and upper WLAN band", IEEE Trans. Antennas Propagat., vol. 57, no. 12, pp. 3942-3950, 2009.

[6] A.A. Gheethan and A.E. Anagnostou, "Dual band-reject UWB antenna with sharp rejection of narrow and closely-spaced bands", IEEE Trans. Antennas Propagat., vol. 60, no. 4, pp. 2071-2076, 2012.

[7] Y.L. Zhao, Y.C. Jiao, G. Zhao, L. Zhang, Y. Song and Z.B. Wong, "Compact planar monopole UWB antenna with band-notched characteristic", Microw. Opt. Tech. Lett., vol. 50, no. 10, pp. 2656-2658, 2008. [8] P. Gao, L. Xiong, J.B. Dai, S. He and Y. Zheng, "Compact printed wide-slot UWB antenna with 3.5/5.5-GHz dual band-notched characteristics", IEEE Antennas Wireless Propag. Lett., vol. 12, no.4, pp. 983-986, 2003.

[9] D.E. Anagnostou, S. Nikolaou, H. Kim, B. Kim, M. Tentzeris and J. Papapolymerou, "Dual band-notched ultra-wideband antenna for 802.11a WLAN enviroments", IEEE APS Int. Symp., pp. 4621-4624, Jun. 10-15, 2007.

[10] K.D. Xu, Y.H. Zhang, R.J. Spiegel, Y. Fan, W.T. Joines and Q.H. Liu, "Design of a stub-loaded ring-resonator slot for antenna applications", IEEE Trans. Antennas Propagat., vol. 63, no. 2, pp.
$517-524,2015$.

[11] D.E. Anagnostou, M.T. Chryssomallis, B.D. Braaten, J.L. Ebel and N. Sepulveda, "Reconfigurable UWB antenna with RF-MEMS for on-demand WLAN rejection", IEEE Trans. Antennas Propagat., vol.62, no. 2, pp. 602-608, 2014.

[12] M. Heino, S.N. Venkatasubramanian, C. Icheln and K. Haneda, "Design of wavetraps for isolation improvement in compact in-band full-duplex relay antennas", IEEE Trans. Antennas Propagat., vol. 64, no. 3, pp. 1061-1070, 2016. 